\title{
Correction to: Wind Tower FRC Foundations: Research and Design
}

\author{
Marco di Prisco, Claudio di Prisco, Giancarlo Fraraccio, \\ Bruno Dal Lago, Paolo Martinelli, Luca Flessati, Matteo Colombo, \\ and Giulio Zani
}

\section{Correction to: \\ Chapter "Wind Tower FRC Foundations: Research \\ and Design" in: P. Serna et al. (Eds.): Fibre Reinforced \\ Concrete: Improvements and Innovations II, \\ RILEM Bookseries 36, \\ https://doi.org/10.1007/978-3-030-83719-8_71}

In the original version of the book, the following belated correction has been incorporated: The author's name changed from "Giulio Zanis" to "Giulio Zani" in Chapter 71 and in the index. The book and the chapter have been updated with the changes. 